ORIGINAL ARTICLE

PRACA ORYGINALNA

\title{
METHODS OF PREVENTIVE INTERVENTION IN WOMEN WITH MULTIPLE PREGNANCIES IN NON-ASSYMPTOMIC CIRCULATION
}

DOI: 10.36740/WLek202002106

\author{
Iryna M. Nikitina, Volodymyr I. Boiko, Svitlana A. Smiian, Alesia V. Boiko, Natalia V. Kalashnyk, \\ Natalia A. Ikonopystseva, Tetiana V. Babar, Maryna A. Bolotna \\ SUMY STATE UNIVERSITY, SUMY, UKRAINE
}

\begin{abstract}
The aim: The purpose of the study is a comparative evaluating the effectiveness of using the different methods of treatment of miscarriage in multiple pregnancies taking into account the condition of the cervix.

Materials and methods: 86 pregnant women with diarrheal twins were monitored. On the basis of studying the premorbid background, somatic and reproductive history, features of the gestational period, leading antenatal risk factors for the development of complications in multiple pregnancies were identified. With the help of transvaginal cervicometry the prognostic ultrasound criteria of the condition of the cervix and its obstructive capacity in case of premature birth are investigated.

Results: In the event of uncomplicated pregnancy multiple birth is characterized by a gradual shortening of the cervix in dynamics from $43.2 \pm 3.9 \mathrm{~mm}$ to $38.2 \pm 4.0 \mathrm{~mm}$ by 20 weeks, from $37.7 \pm 4.1 \mathrm{~mm}$ to $30.2 \pm 3.9 \mathrm{~mm}$ to 30 weeks, to $21.1 \pm 3.1 \mathrm{~mm}$ to 37 weeks. In the period of $25-27$ weeks, the appearance of a V-shaped opening of the uterine cervix in half of the women was observed, which remained until the end of gestation. Shortening of the cervix was the most significant in patients with the risk of abortion who received only tocolytic therapy. In the 2 nd trimester revealed a V- or U-shaped opening of the cervical canal.

In pregnant women at risk who had an obstetric pessary, a decrease in the length of the cervix was found, which was similar to the rate of its shortening in uncomplicated multiple pregnancies. The condition of the cervix in the presence of a pessary before delivery probably did not differ from the condition of the cervix with the normal course of multiple pregnancies.

Conclusions: Pregnant women with uncomplicated multiple pregnancies revealed a decrease in the length of the cervix with an increase in gestation. At the end of pregnancy, the internal jaws acquired a predominantly Y-shape. In pregnant women with the risk of pregnancy termination who received tocolytic therapy, the cervix was the shortest. In late gestation, V-and U-shaped internal jaws were observed. Changes in the cervix after the placement of obstetric pessaries are similar to changes in uncomplicated pregnancy.
\end{abstract}

KEY WORDS: preterm birth, multiple pregnancies, sonographically shortened cervix, unloading obstetric pessary, micronized progesterone

Wiad Lek. 2020;73(2):239-244

\section{INTRODUCTION}

In modern obstetrics, the problem of multiple pregnancies remains extremely relevant and at the same time complicated by the increasing incidence of multiple fertility in the population over the last 15-20 years. Miscarriage is a common complication of pregnancy in women with multiple pregnancy. Premature births are observed in $43.6 \%$ of cases of twin births compared to $5.6 \%$ in single pregnancy $[1,2,3]$. About $17 \%$ of all desired pregnancies are lost, of which 75-80\% are early interruptions, where a downward trend, unfortunately, absent. Deep morphofunctional immaturity on the background of prematurity is a prerequisite for the development of respiratory disorders, non-traumatic intraventricular hemorrhage (IBD), and jaundice of preterm infants, necrotizing enterocolitis, and postnatal encephalopathy. Most preterm infants die intranasally or shortly after birth in intensive care units and some survivors are at high risk of both neonatal mortality and death in subsequent childhood $[4,5,6]$. Approximately $50 \%$ of premature infants remain profoundly disabled, with varying degrees of severity associated with mental and psychomotor retardation, impaired motor, sensory, and communicative functions. The medical and social significance of miscarriage is positioned at its consistently high frequency and high rates of perinatal mortality among premature infants.

The most important pathogenetic mechanisms of miscarriage, according to Sidelnikova V.M. , is an overstretch of the uterine muscles, excessive effect on the neuromuscular system of the uterus humoral and mechanical stimuli on the part of the fetus, which leads to the activation of oxytocin receptors, which increase the number of slit contacts, which causes the frequency of the cervix to increase and initiates the onset of contractile activity of the myometrium. The shortening of the cervix is a consequence of changes in the ratio of its muscle and connective tissues as a result of the reaction of structural components to the action of neuro humoral stimuli $[7,8,9]$.

Interruption of pregnancy on the background of asymptomatic shortening of the cervix occurs in the second to third trimesters, its mechanism is to soften and shorten the cervix due to it smoothing, opening the inner jaws 
and subsequent cervical canal and loss of mechanical support of the fetus. With the increase of intrauterine pressure as the pregnancy develops, the fetal membranes break into the enlarged cervical canal, become infected and ruptured $[7,8,10]$. The latent period from the onset of shortening of the cervix to termination of pregnancy may last from two to 15-16 weeks, during which time the cervix is gradually, without contraction, i.e. asymptomatic, progressively shortened and opens to $3-6 \mathrm{~cm}$ maternity activity sufficiently slight increase in intrauterine pressure, which occurs in multiple pregnancies. For the most part, pregnancy termination begins with a rupture of the fetal membranes. Pregnancy interruption in asymptomatic shortening of the cervix occurs in most cases up to 28 weeks of pregnancy $[1,2,9,10]$. The term of pregnancy $22-27$ weeks is classified as very early preterm birth and in most countries of the world perinatal loss is from the specified gestational term $[3,6,7,8]$. An increase in perinatal morbidity, such as respiratory distress syndrome, intracranial hemorrhage, necrotizing enterocolitis, and delayed effects, including delayed nerve development, cognitive impairment, are associated with premature birth. This category of deeply preterm infants forms a reserve for the improvement of perinatal outcomes as a result of the effective treatment and prevention of premature births. In this regard, an important condition for reducing perinatal morbidity and mortality is the maximum prolongation of pregnancy among at-risk women.

Risk factors for asymptomatic shortening of the cervix are history of infectious diseases (64-82\% of cases), late onset of menarche $(7-12 \%)$ in combination with disorders of the menstrual cycle, the presence of artificial abortions in history, involuntary miscarriages, especially after 10-12 weeks pregnancies, large births or births complicated by cervical trauma, multiple pregnancies $[2,3,7,8]$.

With regard to modern aspects of effective prognosis of preterm birth, the first place among the markers of preterm birth is the determination by cervical length or transvaginal ultrasound cervicometry (TUC) of the cervix length. According to ultrasonography, the criteria for isthmico-cervical insufficiency (ICI) are considered to be progressive shortening of the cervix to $25-20 \mathrm{~mm}$ and the opening of the inner jaws to 8-9 $\mathrm{mm}$. Determining the length of the cervix between the 16-th and 24-th weeks of pregnancy is a more reliable prognostic test for predicting preterm birth than a dynamic study of changes in the length of the cervix during pregnancy. With uncomplicated pregnancy, the technique of determining the length of the cervix allows you to distinguish women from the risk of premature birth. In addition to the length of the cervix, the diameter of the inner jaws (opening more than 5-6 mm), the posterior angle between the body and the cervix is sacralization of the cervix $\left(\geq 90^{\circ}\right)$. There are $\mathrm{Y}, \mathrm{V}$ and $\mathrm{U}$-shaped forms of the inner jaws in the prolapse of the amniotic membranes, with the U-shaped deformation, which is associated with more than $50 \%$ of cases of premature termination of pregnancy $[8,9,10]$. Extension of the internal jaws that in the sonography survey looks like a funnel penetration is a shortening of the cervix, which ultimately leads to the development of preterm birth. Several authors propose to determine the length of the cervix at a critical time for preterm delivery - (16-18 weeks of pregnancy) and in the dynamics every two weeks for timely identification of the risk of premature birth and the use of preventive measures.

Despite numerous attempts to improve the strategy for the prevention of preterm birth in women with multiple pregnancies based on evidence-based medicine, multiple pregnancies are still considered a major risk factor for preterm delivery. The issue of choice for correcting a short cervix is widely discussed in the literature. There are also conflicting opinions about the effectiveness of each of these methods, as the problem of identifying the true cause and mechanisms of cervical shortening is extremely complex. In addition, the lack of dynamic observation does not allow timely adjustment of therapeutic tactics $[9,10]$. One conservative treatment for short cervix is the introduction of an obstetric discharge pessary. Of the modern options for the prevention of preterm birth in multiple pregnancies, the use of progesterone therapy is considered to be the leading one, although this statement is controversial, as well as the use of cervical cerclage methods. In modern obstetrics, both conservative and surgical methods of treating the miscarriage are widely used $[1,2,9,10]$. The conservative method is the use of tocolytic agents, hormone therapy (progesterone preparations) and the use of unloading obstetric pessary. The mechanism of action of the pessary consists in narrowing the internal jaws of the cervix with the inner wall of the pessary, reducing the load on the cervix due to redistribution of the intrauterine pressure of the fetal egg, sacralization of the cervix, and partial transmission of intra-intestinal pressure to the anterior abdominal wall. It was proved the successful using of pessary in pregnant women at risk (late abortions or premature birth), as well as in asymptomatic shortening of the cervix $[1,2,9,10]$.

Preventive cervical stitching is shown for high-risk women who have had a history of two or more involuntary miscarriages or premature births. The suture may be applied for prophylactic treatment purposes in a scheduled or urgent manner. This intervention is shown to be pregnant if the cervical length is less than $25 \mathrm{~mm}$ without the presence or presence of cuneiform cervical canal transformation. Thus in case of multiple fertilities there is no evidence to date the effectiveness of surgical or non-invasive cerclage by using the cervical pessaries to reduce the frequency of early spontaneous births. In patients with short cervix, surgical cerclage even increases the risk of premature birth. Therefore, none of the proposed methods has definite advantages.

\section{THE AIM}

The purpose of the study is a comparative evaluating the effectiveness of using the different methods of treatment of miscarriage in multiple pregnancies taking into account the condition of the cervix. 


\section{MATERIALS AND METHODS}

The study was conducted at the Sumy Regional Clinical Perinatal Center and the Department of Obstetrics and Gynecology of Sumy State University during 2012-2018. There were 86 pregnant women with a dichorrhoid diarrheal twins and a well-defined gestational term, which was defined at 11-13 weeks of gestation. The exceptions were patients with established structural and chromosomal fetal abnormalities. The first group of patients included 20 women with dichorrhagic dyamniotic twins with physiological pregnancy terminated by urgent delivery. This study was approved by the ethics committee of the Sumy State University, Ukraine. All procedures were carried out in accordance with the ethical standards of the responsible committee on human experimentation and with the Helsinki Declaration of 1975, as revised in 2000.

Group II included 24 pregnant women with a dichorionic diamniotic twin who underwent inpatient treatment for 13-36 weeks of pregnancy for the threat of pregnancy termination and preterm delivery and received conservative treatment (tocolytic therapy according to clinical protocol).

Group III examined 10 pregnant women who, due to isthmic-cervical insufficiency, had a suture on the cervix at 14-17 weeks of gestation.

The remaining 32 pregnant women with dichorionic diamniotic twin, who had signs of asymptomatic shortening of the cervix within 14-21 weeks, were included in group IV. As a prophylactic intervention, they were administered an unloading obstetric pessary.

The control group consisted of 40 healthy women with a single pregnancy. The general, somatic, obstetric and gynecological anamnesis, the course of pregnancy and childbirth were investigated. Laboratory studies were conducted on the basis of the clinical laboratory of the "Sumy Clinical Regional Perinatal Center", the laboratory of "Sinevo".

In addition to clinical research methods and conventional laboratory methods, transvaginal ultrasound cervicometry was performed using modern sonoDIAGNJAWST-360 ultrasound machines from Philips (The Netherlands) and "Aloka SSD-2010" (Japan), Japan, using a 6.5 MHz transvaginal sensor. The studies were performed from the 14-th to the 21-st weeks of pregnancy to determine the risk of premature birth by measuring the length of the cervix and calculating the isthmico-cervical coefficient (ICC). The formula for determining the isthmic-cervical coefficient: ICC $=(A+1) / B$, where $A-$ is the depth of the "funnel" of the cervical canal; $B$ - is the length of the intact part of the cervix. ICC value $<0.52$ was considered normal, at which the risk of preterm birth was minimal (Vayssière C. et al., 2005). An increase in ICC $>0.52$ was considered a characteristic predictor of miscarriage.

The technique of performing transvaginal cervicometry was to place the patient in the posterior lithotomy position after pre-emptying the bladder. The ultrasonic sensor was pointed in the direction of the anterior vaginal arches and mounted on the anterior lip of the cervix, while trying not to exert mechanical pressure on the cervix, preventing it from artificial elongation. Examination scan was conducted in the sagittal plane to determine the deviation of the cervix and its position. In addition, its anatomical parameters were measured - the length of the cervical canal, the diameter of the inner cell of the uterus, the length of the isthmus of the uterus. An echogenic endocervical mucosa was used to obtain a sagittal cervical incision. The cervical canal was removed along the entire length in the sagittal plane, with the obligatory visualizing the inner and outer jaws. To measure the length of the cervix, the runners were placed on a triangular echogenic section of the outer jaws and a $\mathrm{V}$-shaped projection of the inner jaws. Parameters were measured when the cervix was enlarged, which occupied $50-75 \%$ of the screen area. Due to periodic contractions of the uterus, the length of the cervix may vary, so the duration of the examination did not exceed 2-3 minutes, taking into account the shortest size. In addition to determining the length of the cervix, the presence of T-, Y-, V-, U-shaped expansion of the internal yawn was also revealed.

The risk of involuntary preterm birth increases exponentially as the cervix is shortened and is inversely proportional to the length of the cervix. After correction by the obstetric unloading pessary, transvaginal ultrasound cervicometry was performed in the position of pregnant woman on the back with bent lower extremities in the hip and knee joints with an empty bladder. The ultrasonic sensor was directed to the anterior vault and placed on the anterior lip of the cervix in the area of the outer jaws.

Transvaginal ultrasound cervicometry after correction with an obstetric unloading pessary was performed on day 3-4, and subsequently in dynamics every 2-3 weeks. The data was recorded in the cervicogram. The choice of tactics for managing a pregnant woman with a pessary on the cervix, depending on the results of cervicometry, was carried out according to the developed algorithms for each group of subjects.

Conservative therapy for the risk of miscarriage was performed according to clinical protocols. Surgical cervical cerclage was performed at 13-16 weeks of pregnancy according to A.I. Lyubimova's method. When vaginal dysbiosis and cervical canal were detected, local vaginal remediation was performed with antiseptic and antifungal agents.

The pessary was administered to pregnant women on an outpatient basis within 14-21 weeks with a shortening of the cervix $<38 \mathrm{~mm}$ and an increase in ICC $>0.52$ to prevent premature birth. In addition to the pessary, a vaginal form of $200 \mathrm{mg}$ micronized progesterone was used. Before the installation of the pessary was performed vaginal examination, bacterioscopic examination of vaginal discharge and cervical canal. If necessary the vagina was rehabilitated. For the prevention of ascending infection, vaginal gel containing decamethoxin, hyaluronic acid and lactate buffer, 8.0 $\mathrm{ml}$ once daily for 10 days, was administered to pregnant women with multiple pregnancies discharge pessaries. During monitoring of women after the introduction of the pessary, a regular examination of vaginal smears was performed. If necessary, the crops were sown from the cervical canal. As a matter of course, the obstetric pessary 
Table 1. The length of the cervix with ultrasound cervicometry $(M \pm m), M M$

\begin{tabular}{|c|c|c|c|c|c|}
\hline $\begin{array}{c}\text { Term of } \\
\text { pregnancy }\end{array}$ & I group & II group & III group & IV group & $\begin{array}{c}\text { Controlled } \\
\text { group }\end{array}$ \\
\hline To 15 weeks & $43,2 \pm 3,9$ & $\begin{array}{c}42,2 \pm 4,0 \\
\text { p1-2 }>0,05\end{array}$ & $\begin{array}{c}22,4 \pm 1,6 \\
p 1-3<0,001 \\
p 2-3<0,001\end{array}$ & $\begin{array}{c}30,4 \pm 3,9 \\
\text { p1-4 }<0,05 \\
\text { p2-4 }<0,05 \\
\text { p3-4 }>0,05\end{array}$ & $42,9 \pm 3,2$ \\
\hline 16-18 weeks & $41,2 \pm 3,8$ & $\begin{array}{c}40,2 \pm 4,6 \\
\mathrm{p} 1-2>0,05\end{array}$ & $\begin{array}{c}22,3 \pm 1,3 \\
\text { p1-3<0,001 } \\
\text { p2-3<0,001 }\end{array}$ & $\begin{array}{c}31,3 \pm 4,3 \\
\text { p1-4 }>0,05 \\
\text { p2-4 }>0,05 \\
\text { p3-4 }>0,05\end{array}$ & $41,2 \pm 3,8$ \\
\hline 19-21 weeks & $38,2 \pm 4,0$ & $\begin{array}{c}33,2 \pm 3,5 \\
\text { p1-2 }>0,05\end{array}$ & $\begin{array}{c}21,5 \pm 1,2 \\
\text { p1-3<0,001 } \\
\text { p2-3<0,001 }\end{array}$ & $\begin{array}{c}30,3 \pm 4,2 \\
\text { p1-4 }>0,05 \\
\text { p2-4 }>0,05 \\
\text { p3-4 }>0,05\end{array}$ & $40,2 \pm 4,0$ \\
\hline 22-24 weeks & $37,7 \pm 4,1$ & $\begin{array}{c}30,7 \pm 3,7 \\
\text { p1-2 }>0,05\end{array}$ & $\begin{array}{c}21,2 \pm 1,5 \\
\text { p1-3<0,001 } \\
\text { p2-3<0,05 }\end{array}$ & $\begin{array}{c}27,5 \pm 3,9 \\
\text { p1-4 }>0,05 \\
\text { p2-4 }>0,05 \\
\text { p3-4 }>0,05\end{array}$ & $39,7 \pm 4,1$ \\
\hline $25-27$ weeks & $33,2 \pm 3,7$ & $\begin{array}{c}26,2 \pm 3,9 \\
\text { p1-2 }>0,05\end{array}$ & $\begin{array}{c}21,3 \pm 1,3 \\
\text { p1-3 }>0,05 \\
\text { p2-3 >0,05 }\end{array}$ & $\begin{array}{c}26,7 \pm 3,8 \\
\text { p1-4 }>0,05 \\
\text { p2-4 }>0,05 \\
\text { p3-4 }>0,05\end{array}$ & $35,2 \pm 3,7$ \\
\hline 28-30weeks. & $30,2 \pm 3,9$ & $\begin{array}{c}22,2 \pm 4,1 \\
p 1-2>0,05\end{array}$ & $\begin{array}{c}21,1 \pm 1,2 \\
p 1-3<0,05 \\
p 2-3>0,05\end{array}$ & $\begin{array}{c}25,1 \pm 4,0 \\
\text { p1-4 }>0,05 \\
\text { p2-4 }>0,05 \\
\text { p3-4 }>0,05\end{array}$ & $33,2 \pm 3,9$ \\
\hline $31-33$ weeks & $27,8 \pm 4,1$ & $\begin{array}{c}23,8 \pm 3,2 \\
\text { p1-2 }>0,05\end{array}$ & $\begin{array}{c}21,8 \pm 1,2 \\
\mathrm{p} 1-3>0,05 \\
\mathrm{p} 2-3>0,05\end{array}$ & $\begin{array}{c}23,8 \pm 3,9 \\
\text { p1-4 }>0,05 \\
\text { p2-4 }>0,05 \\
\text { p3-4 }>0,05\end{array}$ & $31,2 \pm 3,9$ \\
\hline 34-36 weeks & $21,1 \pm 3,1$ & $\begin{array}{c}16,1 \pm 3,1 \\
p 1-2>0,05\end{array}$ & $\begin{array}{c}21,2 \pm 1,1 \\
\text { p1-3 >0,05 } \\
\text { p2-3 >0,05 }\end{array}$ & $\begin{array}{c}21,2 \pm 3,1 \\
\text { p1-4 }>0,05 \\
\text { p2-4 }>0,05 \\
\text { p3-4 }>0,05\end{array}$ & $27,8 \pm 4,1$ \\
\hline
\end{tabular}

p 1-2: reliability of differences between cervical length of pregnant women I and II groups; p 1-3: reliability of differences between cervical length of pregnant women I and III groups; p 1-4: reliability of differences between cervical length of pregnant women I and IV groups; p 2-3reliability of differences between cervical length of pregnant women II and III groups; p 2-4: reliability of differences between cervical length of pregnant women II and IV groups; p 3-4: reliability of differences between cervical length of pregnant women III and IV groups.

was removed at 36 weeks of gestation or with the onset of labor and with the rupture of the fetal membranes. After the removal of the pessary in the absence of delivery within 5-7 days, rehabilitation of the genital tract was performed.

Statistical processing and analysis of the obtained data was performed using «Microsoft Excel» programs using the methods of mathematical statistics and the software package Statistica 8.0. Charts and diagrams were built using «Microsoft Excel». Mathematical processing of indicators was performed using the methods of variation statistics for comparing inhaled sets by averages using the t-Student test.

\section{RESULTS AND DISCUSSION}

The surveyed groups were homogeneous in composition and representative. The average age of pregnant women of group I was $27.8 \pm 4.5$ years, II $-27.0 \pm 4.2$ years, III $-26.0 \pm$ 4.2 years, in pregnant women of group IV $-26.0 \pm 3.8$ years, in the control group $-27.6 \pm 3.2$ years $(p>0.05)$. There were no differences in age, somatic pathology, and incidence of obstetric history between the control and main groups.

Pregnancy was the first in $6(30.0 \%)$ women of the first group, and the second one was repeated. Preliminary pregnancies have ended with immediate delivery. There were no cases of involuntary or artificial termination of pregnancy. Pregnancy was the first in $2(8.3 \%)$ women in group II, and in 22 cases it was repeated. Medical or involuntary abortions had a history of 8 (33.3 \%) women. All patients in group III were re-pregnant. Of these, $8(80.0 \%)$ previous pregnancies ended in preterm delivery, $9(90.0 \%)$ women had a history of involuntary miscarriages and abortions. All women of group IV were repregnant. Of 
these, 23 (71.9\%) previous pregnancies ended in preterm delivery. A history of $9(28.1 \%)$ women had involuntary miscarriages and artificial abortions.

Women with uncomplicated pregnancy were observed on an outpatient basis. Pregnant II, III, and IV groups were hospitalized in connection with the threat of termination of pregnancy starting at 13-18 weeks for comprehensive examination and treatment.

Women with uncomplicated multiple pregnancies are characterized by asymptomatic shortening of the cervix as pregnancy increases from the first study to 20 weeks from $43.2 \pm 3.9 \mathrm{~mm}$ to $38.2 \pm 4.0 \mathrm{~mm}$. At $22-30$ weeks of gestation, the rate of shortening increased from $37.7 \pm 4.1$ $\mathrm{mm}$ to $30.2 \pm 3.9 \mathrm{~mm}$. Further, the length of the cervix progressively decreased and reached 37.1 weeks at $21.1 \pm$ $1.1 \mathrm{~mm}(\mathrm{p}<0.001)$. At $25-27$ weeks, Y-shaped opening of the uterine owl was noted in more than half of pregnant women. At 34-36 weeks, a Y-shaped form was detected in 22 (91.7\%) women; a V-shaped internal yawn was detected in $2(8.3 \%)$ women.

In patients receiving traditional tocolytic therapy in connection with the appearance of the clinic of the threat of abortion, shortening of the cervix from $42.2 \pm 4.0 \mathrm{~mm}$ to 33.2 $\pm 3.5 \mathrm{~mm}$ was observed by 19 to 21 weeks. In each case, it depended on the duration of the pregnancy in which the pregnant woman addressed the threat of abortion. Significant shortening was observed from 22 to 30 weeks of gestation, when the length of the cervix was respectively $30.7 \pm 3.7 \mathrm{~mm}$ and $22.2 \pm 4.1 \mathrm{~mm}$. At $34-36$ weeks, the length of the cervix was $16.1 \pm 3.1 \mathrm{~mm}(\mathrm{p}<0.001)$. The appearance of Y-shaped opening of the uterine owl was observed in the period from 21-22 weeks to 27 weeks of pregnancy - in 22 (91.7\%) pregnant women. After 30 weeks, a V-shaped or U-shaped opening of the inner jaws was observed in all pregnant women, a U-shaped was more commonly noted shortly before birth.

In transvaginal cervicometry was found that shortening of the cervix during multiple births was more pronounced group III dinner compared to women with uncomplicated pregnancy, which up to 15 weeks was $22.4 \pm 1.6 \mathrm{~mm}$ (Table 1 ).

This was an indication for suturing the cervix at 13-16 weeks. In the group of women who underwent surgical treatment of ICN, the length of the cervix by the end of pregnancy decreased to $21.2 \pm 1.1 \mathrm{~mm}(\mathrm{p}>0.05)$, which leads to the conclusion that the cervix is fairly stable. At $22-23$ weeks, 2 (20.0\%) pregnant women in this group had a Y-shaped opening of the inner jaws, and the remaining inner jaws was T-shaped. In the third trimester of pregnancy, a V- or U-shaped opening of the internal jaws was not observed. The obstetric pessary was installed at the length of the cervix $31.3 \pm 4.3 \mathrm{~mm}$. In the future, there was a moderate gradual decrease in its length to $21.1 \pm 3.1 \mathrm{~mm}$ $(\mathrm{p}>0.05)$. A Y-shaped change in the inner jaws appeared at 22-24 weeks of gestation and was observed after 30 weeks of gestation in 21 (65.6\%) of the examined patients.

An additional criterion that influenced the effects of pregnancy was the condition of the cervical canal and the inner jaws. It was noted that the earlier the birth occurred, the more significant were the changes in the length of the cervix, which were manifested not only by its shortening, but also by a V- or U-shaped opening of the inner jaws and the cervical canal. When comparing the condition of the cervix in women of the group with the normal course of multiple pregnancies and the group where the pessary was installed, it can be noted that the length of the cervix was almost indistinguishable before birth and was $21.1 \pm 3.1 \mathrm{~mm}$ and $21,2 \pm 3.1 \mathrm{~mm}$, respectively ( $\mathrm{p}>$ 0.05 ), although if there were signs of a pregnancy termination threat before setting the pessary, it was much shorter (Table 1 ).

The condition of the internal jaws in the second and third trimesters was almost indistinguishable. The Y-shaped change in the internal pharynx predominated. This leads to the conclusion that the obstetric pessary brings pregnancy closer to the physiological course. The use of unloading obstetric pessary in combination with the vaginal form of micronized progesterone is proved to be associated with an increase in the duration of the latent period from establishing the diagnosis of asymptomatic shortening of the cervix to the onset of spontaneous labor by an average of $14.9 \%$ due to the probabilistic effects.

Urgent delivery in patients treated with tocolytic therapy was significantly less frequent than in women with uncomplicated pregnancy ( $45 \%$ and $80 \%$, respectively, $\mathrm{p}<0.05)$. In women after using surgical cervical cerclage and obstetric pessary for prevention of miscarriage, the proportion of urgent childbirth was not significantly different $(60.0 \%$ and $66.6 \%$, respectively, $\mathrm{p}<0.05)$ and did not differ significantly from the examined group I ( $80.0 \%$, $\mathrm{p}<0.05$ ), which proves their high efficiency.

The course of childbirth was complicated by premature rupture of the fetal membranes equally frequently $(\mathrm{p}<0.05)$ in pregnant women of all groups: in $2(10.0 \%)$ patients in group I, in $5(20.8 \%)$ women in group II, in 4 (40.0 \%) of pregnant women of group III, in 5 (15.6\%) women of group IV. The anhydrous interval did not exceed $8.3 \pm 1.6 \mathrm{~h}, 9.4 \pm 2.1 \mathrm{~h}, 8.9 \pm$ $1.5 \mathrm{~h}$, and $6.5 \pm 1.4 \mathrm{~h}$, respectively, and did not differ between the pregnant women $(\mathrm{p}<0.05)$. The average duration of labor did not differ significantly and was $12.6 \pm 2.3 \mathrm{~h}$ in women of group I, $9.1 \pm 1.5 \mathrm{~h}-$ in II, $9.3 \pm 1.9 \mathrm{~h}-$ in III, and $10,4 \pm 2.3$ $\mathrm{h}$ - in group IV. The average volume of blood loss in childbirth through the natural birth canal was almost the same $(\mathrm{p}<0.05)$ and was in women of group I $310.5 \pm 20.2 \mathrm{ml}, \mathrm{II}-317.4 \pm 31.6$ $\mathrm{ml}$, III $-320,0 \pm 25.5 \mathrm{ml}$, group IV $-290.4 \pm 37.2 \mathrm{ml}$. There were no cases of pathological blood loss during childbirth due to natural birth pathways in all groups.

Birth by caesarean section was performed in $3(15.0 \%)$ pregnant women of group I, in $4(16.7 \%)$ patients of group II, in $2(20.0 \%)$ women of group III and in $4(12.5 \%)$ of pregnant women group IV.

There were no perinatal losses in patients in groups I and IV. In women of groups II and III were killed one newborn in the early neonatal period. In the study of the condition of neonatal adaptation of the newborn surveyed groups the following results were obtained. The average weight of newborns in group 1 was $3230 \pm 272 \mathrm{~g}$, in group II -2895 $\pm 355 \mathrm{~g}$, in group III $-2730 \pm 355 \mathrm{~g}$, in IV $-3064 \pm 233 \mathrm{~g}$ $(p>0.05)$. Assessment of the condition of newborns on the 
Apgar scale at 1 and 5 minutes did not differ significantly and was respectively in the infants of group I $-7.5 \pm 1.5$ points and $8.2 \pm 1.6$ points, in group II $-7.6 \pm 1.5$ score and $8.3 \pm 1.5$ points, in group III $-7.4 \pm 1.7$ and $8.4 \pm 1.5$ points, in IV $-7.4 \pm 1.5$ points and $8.5 \pm 1.4$ points.

\section{CONCLUSIONS}

1. In women with uncomplicated course of multiple pregnancies there is a gradual shortening of the cervix as gestation increases. By the end of pregnancy, the inner yawn is predominantly Y-shaped.

2. In pregnant women with the risk of preterm delivery, which underwent tocolytic therapy, the cervix was significantly shortened early in gestation. At the end of pregnancy, a V- or U-shaped cervical canal was observed.

3. The condition of the cervix remained stable after the operation for correction of isthmic-cervical insufficiency. The length of the cervix was more dependent on the initial obstetric situation.

4. The condition of the cervix after the installation of an obstetric discharge pessary corresponded to the rate of its shortening in uncomplicated multiple births. Before delivery, the condition of the cervix in the presence of obstetric pessary did not differ from that of patients with normal multiple pregnancies.

5. The use of obstetric pessary is an effective method of treatment and prevention of miscarriage in patients with multiple pregnancies, reduces the incidence of late abortion, preterm delivery and perinatal losses.

\section{REFERENCES}

1. Bespalova 0.N., Sargsyan G.S. Vybor metoda korrekcii ismiko-cervikal'noj nedostatochnosti. [Choice of method of correction of ismico-cervical insufficiency]. Journal of Obstetrics and Women's Diseases. 2017; 3: 153-168.

2. Bespalova 0.N., Sargsyan G.S. E'ffektivnost'primeneniya akusherskogo pessariya pri ugrozhayuschikh prezhdevremennykh rodakh $\mathrm{i}$ korotkoj shejke matki. [Effectiveness of the use of obstetric pessary in threatening preterm labor and short cervix]. Medical Council. 2017; 13: 118-126. doi: 10.21518/2079-701X-2017-13-118-126.

3. Krasnopolsky V.I., Novikova S.V., Zharova A.A., et al. Vedenie beremennosti i rodov pri mnogoplodnoj beremennosti. [Management of pregnancy and childbirth in multiple pregnancies]. Almanac of clinical medicine. 2015; 37: 32-40.

4. Egorova A.T., Ruppel N.I., Maiseenko D.A., et al. Techenie beremennosti i rodov pri spontannom mnogoplodii i odnoplodnoy beremennosti. [The course of pregnancy and childbirth in case of spontaneous multiple birth and single-pregnancy]. Scientific papers of Belgorod State University. Series: Medicine. Pharmacy. 2015;10 (207):75-80.

5. Rogova E.V., Barinov S.V., Dolgikh T.l., et al. Znachenie faktora rosta placenty v geneze oslozhnenij pri mnogoplodnoj beremennosti [Significance OfPlacental Growth Factor In The Genesis Of Complications In Multiple Pregnancy]. Zdorov'e zhenschiny. 2013;9(85):84-86.

6. Sichinava, L G. Mnogoplodie. Sovremennye podkhody k taktike vedeniya beremennosti [Current approaches to management of multiple pregnancies]. Akusherstvo, ginekologiya i reprodukciya. 2014;2(8):131-137.
7. Yaremchuk L. V. Mozhlyvosti transvahinalnoi ekhohrafii v diahnostytsi istmikotservikalnoi nedostatnosti [Transvaginal echography's possibilities in diagnostics of isthmic-cervical insufficiency]. Vistnyk morfolohii, 2014; 1(20): 92-95.

8. Nikitinal.,BoychukA.,BabarT.,etal.Prediction of threats to multiplepregnancy interruption depending on the cause of its occurrence. Research Journal of Pharmaceutical, Biological and Chemical Sciences. 2016; 7:764 - 771.

9. Nikitina I., Boychuk A., Kalashnik N., et al. Immunomorphological features of the placenta in multiple pregnancies. Georgian medical news. 2016; 6: 12-17.

10. Brown R., Gagnon R., Deliste M. F. Cervical insufficiency and cervical cerclage. Obstet Gynaecol Can. 2013; 35(12): 1115-1127. doi: 10.1016/ S1701-2163(15)30764-7.

11. Mendoza M., Goya M., Gascon A., et al. Modification of cervical length alter cervical pessary insertion: correlation weeks of gestation. Matern Fetal Neonatali Med, 2017; 30(13): 1596-1601. doi: 10.1080/14767058.2016.1216538.

12. Saccone G., Giardulli A., Xodo S., et al. Cervical Pessary for Preventing Preterm Birth in Singleton Pregnancies With Short Cervical Length: Systematic Review and Meta-analysis. Ultrasound Med, 2017; 36(8): 1535-1543. doi: 10.7863/ ultra.16.08054.

The work is carried out within the framework of the research work "Optimization of diagnosis and prevention of diseases of the reproductive system and development of pathogenically grounded methods for their correction" (state registration number 011U001801).

\section{ORCID and contributionship:}

Iryna M. Nikitina - 0000-0001-6595-2502 A,E,F

Volodymyr I. Boiko - 0000-0001-6069-4268 ${ }^{\mathrm{C}}$

Svitlana A. Smiian - 0000-0002-7679-2302 B,D

Tetiana V. Babar - 0000-0002-5889-2429 ${ }^{E}$

Natalia V. Kalashnyk - 0000-0003-1515-9105 ${ }^{B}$

Alesia V. Boiko - 0000-0002-6994-7564 ${ }^{\mathrm{F}}$

Natalia A. Ikonopystseva - 0000-0002-8668-724X ${ }^{F}$

Maryna A. Bolotna - 0000-0003-1982-9022 D

\section{Conflicts of interest:}

Authors declare no conflict of interest.

\section{CORRESPONDING AUTHOR Iryna M. Nikitina}

Department of Obstetrics and Gynecology

Sumy State University

Lermontova str. 1A/112, Sumy, 40030, Ukraine

tel: +380662947360

e-mail:nikitina1med@gmail.com

Received: 04.05 .2019

Accepted: 25.12.2019

A - Work concept and design, B - Data collection and analysis, C - Responsibility for statistical analysis,

D-Writing the article, $\mathbf{E}$-Critical review, $\mathbf{F}-$ Final approval of the article 